\title{
TRABALHO, EDUCAÇÃO E JUVENTUDES: DIÁLOGO COM O PENSAMENTO SOCIAL DE CHRISTIAN LAVAL E PIERRE DARDOT
}

\author{
WORK, EDUCATION AND YOUTHS: A DIALOGUE WITH THE SOCIAL \\ THINKING OF CHRISTIAN LAVAL AND PIERRE DARDOT
}

Roberto Rafael Dias da Silva ${ }^{1}$ (D) (0000-0001-6927-3435)

${ }^{1}$ Universidade do Vale do Rio dos Sinos, Programa de Pós-Graduação em Educação, São Leopoldo, Rio Grande do Sul, Brasil. <robertoddsilva@yahoo.com.br>

Resumo O presente estudo teórico propõe um diagnóstico crítico das relações entre trabalho, educação e juventudes contemporâneas, por meio de um breve diálogo com o pensamento social de Christian Laval e Pierre Dardot. Sua preocupação central encontra-se na emergência de novos arranjos subjetivos no contexto do neoliberalismo. Para pensar tais relações foram considerados três traços conceituais derivados das obras dos autores selecionados: a compreensão da crise como modo de vida permanente, a ênfase nos aspectos emocionais e no dispositivo desempenho/gozo e a reinscrição da formação juvenil no território do comum. Ao longo do estudo, evidencia-se que um referencial analítico crítico e heterodoxo, sustentado numa releitura específica do pensamento de Marx articulada a outras contribuições, da forma como tratado por Dardot e Laval, apresenta potencialidade heurística significativa para pensar os conceitos de trabalho, educação e juventude no contexto brasileiro atual.

Palavras-chave educação; trabalho; juventude; sociologia da educação.
Abstract The present theoretical study proposes a critical diagnosis of the relationships among work, education, and contemporary youths through a brief dialogue with the social thinking of Christian Laval and Pierre Dardot. Its main concern lies in the rise of new subjective arrangements within the context of neoliberalism. In order to think of these relationships, we have considered three conceptual traits derived from the works of the selected authors: the understanding of the crisis as a permanent way of life, the emphasis on the emotional aspects and on the performance/enjoyment device, and the reassignment of youth training to the territory of the common. Throughout the study, it is evidenced that an analytical, critical, and unorthodox framework, backed by a specific reinterpretation of Marx's thinking combined with other contributions, as treated by Dardot and Laval, displays a significant heuristic potentiality to think about the concepts of work, education, and youth in the current Brazilian context.

Keywords education; work; youth; sociology of education. 


\title{
Introdução
}

\begin{abstract}
Mas não devemos ignorar as mutações subjetivas provocadas pelo neoliberalismo que operam no âmbito do egoísmo social, da negação da solidariedade e da redistribuição e que podem desembocar em movimentos reacionários e até neofascistas. (Dardot e Laval, 2016, p. 9).
\end{abstract}

Os debates em torno das relações entre trabalho, educação e juventude, sob diferentes perspectivas teóricas, evidenciam-se como um campo academicamente produtivo e relevante. São inúmeros os estudos que, há mais de duas décadas, direcionam reflexões para a questão da formação dos trabalhadores, para os sentidos da profissionalização, para uma crítica aos modelos de formação desenvolvidos no Ensino Médio, ou mesmo para uma ressignificação da própria formação humana, que se dá na interface com o mundo do trabalho (Kuenzer, 2007; Saviani, 2007; Frigotto, 2011). Podemos, então, registrar a pertinência dessas reflexões, ou, como sugere a caracterização sociológica de Richard Sennett (2006), precisaríamos reinscrever esse debate nas condições formativas de uma 'cultura do novo capitalismo'.

Ainda que as abordagens de inspiração neomarxista tenham sua relevância no campo (Frigotto, 2011), cada vez mais os estudos sobre educação e trabalho evidenciam uma aproximação com abordagens sociológicas mais heterodoxas, muitas delas de caráter compreensivo e humanista (Lima, 2010; Hennington, Cunha e Fischer, 2011). Inspirados nessa tendência, neste texto produziremos algumas aproximações com o pensamento social de Christian Laval e Pierre Dardot, mapeando possibilidades teóricas, advindas de suas obras, para a reflexão em torno das relações entre educação e trabalho ${ }^{1}$. De forma geral, buscaremos posicionar este debate nos estudos produzidos no Brasil acerca de tais relações. Com base nessa escolha teórica, importa destacar as possibilidades analíticas advindas deste pensamento para problematizar as hodiernas questões educacionais.

A referida temática adquire relevância e pode ser justificada no contexto da educação brasileira contemporânea, sobretudo devido ao atual estágio de desenvolvimento capitalista em curso no país, associado à constituição de uma "nova morfologia do trabalho" (Antunes, 2014a, p. 42). De acordo com Ricardo Antunes, ao historicizarmos o desenvolvimento econômico do Brasil, podemos indicar que "o capitalismo brasileiro, de desenvolvimento hipertardio quanto ao seu modo de ser, vivenciou, ao longo do século XX, um verdadeiro processo de acumulação industrial, especialmente a partir do getulismo" 
(Antunes, 2014b, p.12). Mesmo que a industrialização tenha sido promovida tardiamente, os processos derivados das mudanças no mundo produtivo potencializadas pela emergência do capitalismo flexível - redimensionaram a economia brasileira nas últimas duas décadas.

De acordo com o autor, sob essas novas condições, emerge no Brasil uma nova 'morfologia do trabalho' demarcando, inclusive, outros arranjos subjetivos para a classe trabalhadora. Em suas palavras, trata-se do "resultado de um monumental processo de reestruturação produtiva desencadeado desde o início dos anos 1970 nos países centrais, e especialmente desde meados dos anos 1980 nos países do Sul" (Antunes, 2014a, p.39). A flexibilidade, a precarização e a informalidade, na perspectiva defendida pelo sociólogo brasileiro, demarcariam a referida morfologia. Acompanha a produção deste cenário, vale salientar, "o desmonte da legislação social protetora do trabalho" (Antunes, 2014 b, p. 24). Ampliando o escopo dessa argumentação, a leitura proposta por Pochmann $(2013$; 2014) sugere novos desafios, inclusive, para o processo de desenvolvimento econômico em curso no Brasil.

Antunes, em um exercício de síntese, defende que "a articulação complexa existente entre financeirização da economia, reestruturação produtiva e as mutações no espaço microcósmico do trabalho e da empresa não poderia deixar de afetar a classe trabalhadora" (2014a, p. 40). Considerando as condições acima expostas, tratadas especificamente desde o contexto brasileiro, neste texto apresentaremos um conjunto de contribuições do pensamento social contemporâneo para pensar as relações entre trabalho, educação e juventude, nos marcos hodiernos da escolarização de nosso país. Valendo-nos da hipótese proposta por Antunes, em torno de uma nova morfologia do trabalho no Brasil, buscaremos derivações dos estudos de Dardot e Laval para o tratamento analítico desta questão. Ainda que os autores não produzam teorizações no âmbito educacional, seus estudos são cada vez mais lidos e reconhecidos, internacionalmente, para a compreensão dos processos de formação humana (Lima, 2012; Silva, 2018).

Para fins deste texto, priorizaremos três perspectivas advindas do pensamento social de Dardot e Laval, buscando circunscrevê-las aos debates contemporâneos sobre educação e trabalho engendrados no contexto brasileiro. Inicialmente, na primeira seção, revisitaremos o diagnóstico acerca da emergência de novas formas subjetivas no contexto do capitalismo contemporâneo, cotejando-as com as questões da financeirização da vida e a individualização das pautas formativas. A seguir, na segunda seção, esboçaremos uma revisão conceitual de algumas obras de Dardot e Laval, priorizando examinar a perspectiva do neoliberalismo como uma racionalidade organizadora da vida atual e, em contrapartida, as possibilidades críticas derivadas do conceito de comum. Por fim, em uma abordagem mais propositiva, valendo-nos das duas 
últimas obras elaboradas pelos pensadores franceses, traduzidas e publicadas no Brasil, delinearemos alguns traços conceituais de suas obras como alternativas de pensamento para fomentar outros debates acerca das relações entre trabalho e educação.

\section{O diagnóstico do capitalismo contemporâneo e as novas subjetividades}

Para construirmos um breve diagnóstico acerca das novas relações estabelecidas entre trabalho, educação e juventudes contemporâneas, em perspectiva crítica, precisamos reconhecer a multiplicidade de perspectivas teóricas que favorecem a composição de problematizações acerca desta temática. Variadas abordagens derivadas de matrizes conceituais diferentes - como a Sociologia, a História, a Filosofia e a Psicologia - permitem que possamos caracterizar com maior amplitude e profundidade as permanentes mutações subjetivas engendradas nas condições deste cenário. De modo a introduzir esta seção, poderíamos interrogar: Quais concepções formativas derivam-se das variadas mudanças ocorridas no mundo do trabalho? Como as juventudes contemporâneas têm sido reposicionadas nas tramas do neoliberalismo? Do ponto de vista cultural, o que torna possível a emergência de novos agenciamentos educativos para as juventudes? Buscaremos algumas perspectivas sociológicas para examinarmos atentamente estas questões.

Em tais condições, de acordo com Lipovetsky (2004), podemos sinalizar para a emergência de uma nova forma de individualismo - de forma paradoxal - na qual o indivíduo evidencia uma obsessão por si mesmo e, ao mesmo, agonia-se por suas incapacidades e pelos dilemas da vida contemporânea. De acordo com o filósofo, “a obsessão de si, hoje, manifesta-se menos pela febre de prazer e de gozo que pelo modo da doença e da idade, a medicalização da vida" (p. 20). Vale reforçar a ênfase na mobilidade subjetiva.

Doravante, cada um se quer autônomo para construir livremente, à la carte, o seu ambiente pessoal. Vivemos a época da mobilidade subjetiva. Cada um se serve. Fica o problema para aqueles que não conseguem ter acesso a essa mobilidade, convertida num imperativo das democracias liberais (Lipovetsky, 2004, p. 21).

Esboça-se também, neste contexto, novas relações éticas e outros modos de convivência democrática nomeadas pelo filósofo como "era pós-moralista" ou "crepúsculo do dever" (Lipovetsky, 2004, p. 26). Em tais relações, "a exigência ética está cada vez mais presente, mas, ao mesmo tempo, não se reclama mais dos indivíduos devoção, doação de si, sacrifício de qualquer ordem ou viver para o outro" (Lipovetsky, 2004, p. 24). A era pós-moralista, então, não se caracteriza por grandes princípios de ação coletiva, sistemas morais 
coletivos ou mesmo sacrifícios por uma causa maior. Em termos subjetivos, ainda de acordo com Lipovetsky, o crepúsculo não significa o desaparecimento do dever; mas, "da eliminação da retórica maximalista das obrigações e, simultaneamente, da consagração do dever mínimo e livre” (2004, p. 31).

No que tange a estas dimensões subjetivas, sob outro prisma reflexivo, Safatle (2008) destaca que parece estar em declínio a internalização da ética protestante do trabalho, anunciada por Max Weber. Na ética weberiana, “o trabalho que marcava o capitalismo como sociedade de produção era uma atividade que não visava exatamente o gozo do serviço dos bens, mas a acumulação obsessiva" (p. 120). As relações com o trabalho atualmente engendradas deslocam-se da lógica da produção para o consumo. Isto é, delineia-se uma nova ética.

O mundo do consumo pede, por sua vez, uma ética do direito ao gozo. Pois o que o discurso do capitalismo contemporâneo precisa é da procura do gozo que impulsiona a plasticidade infinita da produção das possibilidades de escolha no universo do consumo. Ele precisa da regulação do gozo no interior de um universo mercantil estruturado (Safatle, 2008, p. 126).

Diferentemente da ética protestante em que, do ponto de vista subjetivo, explicitava-se uma repressão ao gozo; atualmente vê-se o gozo como "um imperativo" (Safatle, 2008, p. 128). Mais que isso, descreve-nos Safatle (2008), "a incitação e a administração do gozo se transformaram na verdadeira mola propulsora da economia libidinal da sociedade de consumo" (p. 128). Conforme evidenciamos até este momento, emergem contemporaneamente novos modos de construção das subjetividades - seja pelo declínio da ética sacrificial (Lipovetsky, 2004), seja pelo imperativo ao gozo como um modo de relação consigo mesmo, com a cultura e com o trabalho (Safatle, 2008). A seguir ampliaremos este diagnóstico direcionando-nos para a financeirização da vida e para a intensificação das desigualdades, típicas do capitalismo atual.

De acordo com a socióloga Saskia Sassen (2016), em termos de economia política, poderíamos diagnosticar o "surgimento de novas lógicas de expulsão" (p. 9). Para além de argumentar em torno das injustiças crescentes ou da intensificação das desigualdades sociais, conhecidas patologias do capitalismo contemporâneo, a autora defende que "essas expulsões podem coexistir com o crescimento econômico tal como é medido pelas formas tradicionais" (Sassen, 2016, p. 10). Os instrumentos de uma sociedade financeirizada, as políticas ambientais, as pessoas em deslocamento, a precarização da vida nas novas formas de intermitência no mundo do trabalho ou mesmo o crescimento no 
número de prisões privadas seriam alguns dos variados canais de expulsão que vemos serem ampliados neste começo de século.

Importa esclarecer, todavia, que "o caráter, o conteúdo e o local dessas expulsões variam enormemente, atravessando estratos sociais e condições físicas no mundo inteiro" (Sassen, 2016, p. 11). Com os processos de globalização e a complexificação dos instrumentos técnicos derivados, tornou-se recorrente explicar as condições sociais e ambientais sob uma espécie de gramática da financeirização. Em linhas gerais, "isso nos levou à disposição de 'financeirizar' até mesmo a subsistência daqueles que perderão tudo se o instrumento não funcionar como se esperava" (p. 13). O caso emblemático dessa condição são as hipotecas subprimes empregadas nos Estados Unidos desde o início da última década.

Desmembrar o social por meio de uma desigualdade extrema trata-se de uma das principais tendências sistêmicas para fabricar as expulsões. Em torno dessa questão, a hipótese mobilizada pela socióloga é que "debaixo das características específicas das diversas crises globais existem tendências sistêmicas emergentes conformadas por algumas poucas dinâmicas básicas" (Sassen, 2016, p. 15). A nova fase do capitalismo global, por meio de suas operações complexas e inovações permanentes, e após três décadas de grande desenvolvimento, atualmente se depara com 'economias em contração' em todo o mundo. Essa condição econômica favorece as lógicas da expulsão, visto que nas décadas antecedentes mobilizavam-se lógicas de incorporação.

Assim sendo, parece evidenciar-se a conformação política de um capitalismo que opera de forma centrífuga, empurrando para fora aqueles que não estão se movimentando ${ }^{2}$. Todavia, de forma ambivalente, sobre os jovens incorporados ao mundo do trabalho, parece evidenciar-se outra lógica. Do ponto de vista da subjetividade juvenil, alguns aspectos merecem destaque. Chama a atenção, inicialmente, a emergência de modos de "violência neuronal" (Han, 2012, p. 26). Byung-Chul Han (2012), em obra filosófica recente, argumenta que os sujeitos contemporâneos são constituídos sob as condições de uma sociedade do rendimento, estabelecendo relações de autoexploração, em permanente guerra consigo mesmo. Porém, em sua perspectiva, “o sujeito da autoexploração se torna presa de um cansaço infinito. É a figura originária da sociedade do cansaço" (Han, 2012, p. 9). A hipótese da sociedade do cansaço, esboçada por Han, supõe a emergência de determinadas formas de "violência neuronal", que também nos permitem ampliar o escopo argumentativo acerca das relações entre subjetividade e trabalho ${ }^{3}$.

Em termos destas relações, os indivíduos tornam-se empreendedores de si mesmos e, dessa forma, movidos 'pela pressão por rendimento'. Importante esclarecer também que o sujeito do rendimento age voluntariamente, sem coação externa, sendo "ao mesmo tempo vítima e verdugo de si mesmo" (Han, 
2012, p. 30). Sua relação com o tempo é aproximada a uma administração multitarefas (multitasking).

A técnica de administração do tempo e atenção multitasking não significa um progresso para a civilização. O multitasking não é uma habilidade para a qual esteja capacitado unicamente o ser humano tardomoderno da sociedade do trabalho e da informação. Se trata melhor de uma regressão. De fato, o multitasking está amplamente estendido entre os animais selvagens (Han, 2012, p. 33 - grifos nossos).

A ênfase no multitasking e suas formas de atenção, em linhas gerais, explicitam um conjunto de destrezas e habilidades específicas requeridas para os jovens contemporâneos. As lógicas do rendimento expõem estes sujeitos a condições subjetivas cada vez mais individualizantes e competitivas, nas quais em seus limites são esboçadas as frágeis linhas de uma 'sociedade do cansaço' (Han, 2012). As ressonâncias psíquicas do "novo espírito do capitalismo" (Boltanski e Chiapello, 2009), com o declínio da sociedade do trabalho, permitiram que as experiências ambivalentes da intensificação e da precarização adquirissem centralidade. André Gorz (2005), ao descrever as novas formas de trabalho imaterial em uma indústria multinacional, argumenta que os conhecimentos e as qualificações profissionais não são consideradas centrais para a formação dos trabalhadores. Em suas palavras, o que passa a contar "são as qualidades de comportamento, as qualidades expressivas e imaginativas, o envolvimento pessoal na tarefa a desenvolver e completar" (p. 17). A seguir, em sintonia com os argumentos apresentados neste diagnóstico de caráter heterodoxo, direcionaremos nossa reflexão para as obras recentes de Dardot e Laval procurando desenhar um diagnóstico das novas gramáticas políticas emergentes no início deste século.

\section{O diagnóstico das novas gramáticas políticas: os estudos de Dardot e Laval}

A recente divulgação em nosso país das obras de Pierre Dardot e Christian Laval, reconhecidos pensadores sociais franceses, trouxe um conjunto de novas interrogações para as pesquisas em Ciências Humanas, em geral, e para os estudos educacionais, de forma específica. Ao proporem uma releitura bastante instigante da obra de Karl Marx, sobretudo por meio de uma articulação com os estudos foucaultianos sobre a biopolítica, os diretores do seminário "Question Marx" adquiriram significativa visibilidade acadêmica em todo o mundo. A crítica ao neoliberalismo como razão do mundo e do comum como princípio político alternativo têm sido muito estudadas e esta breve seção propõe-se a realizar um exercício propedêutico de contextualização das obras para, ao final, mapear implicações para o campo educacional 
em nosso país, sobretudo no que tange às relações entre trabalho, educação e juventudes contemporâneas.

Para iniciarmos, consideramos pertinente compreender o quadro de interrogações que perpassou a criação do Seminário "Question Marx", no ano de 2004. O referido grupo foi criado com a finalidade de "reinterrogar o quadro teórico e a base histórica da crítica social e política que foi o pensamento de Marx" (Dardot e Laval, 2015, p. 275). Como argumentaram em entrevista recente, publicada no Brasil pela revista Tempo Social, suas intenções acadêmicas não estavam em retornar às bases do pensamento marxiano, mas na busca por novas possibilidades de interpretação para o capitalismo atual. Chama a atenção também o fato de que os pensadores têm uma larga trajetória de aproximação aos movimentos sociais e políticos; todavia, reafirmam que não se trata de uma questão de pertencimento. Trata-se de uma posição de interlocução, posição esta que mantém inclusive com o mundo acadêmico (visto que ainda se veem como outsiders). Tal atitude intelectual, sob sua perspectiva, supõe uma releitura do campo acadêmico. A dualidade entre intelectuais universais e intelectuais específicos, típica do debate francês dos anos de 1970, precisaria ser ampliada para a recomposição de nosso trabalho e de nossas inquietações.

Vivemos em uma época de descompartimentalização, de hibridações, de fertilizações recíprocas. As teorias e as disciplinas se articulam, os estudiosos e os filósofos de comunicam entre eles, os laboratórios e as instituições mais produtivas são interdisciplinares. Em outras palavras, estamos assistindo a uma recomposição do campo intelectual pela intensificação das práticas "transfronteiriças" (Dardot e Laval, 2015, p. 280 - grifos no original).

Mobilizando certas práticas transfronteiriças que os pensadores sociais, ao examinarem a sociedade neoliberal, encontraram no curso "Nascimento da Biopolítica", de Michel Foucault, a possibilidade de ampliar seu escopo interpretativo. Em sua obra $A$ nova razão do mundo, publicada originalmente em 2009, Dardot e Laval (2016) levaram adiante a hipótese foucaultiana de que o neoliberalismo é uma racionalidade política, capaz de engendrar um novo sistema normativo que, com maior ou menor intensidade, estende-se a todos os campos da vida humana. Ampliaremos a seguir alguns aspectos gerais sobre esta obra.

Após a crise econômica de 2008, avançava nos Estados Unidos e na Europa a hipótese de que se tratava do fim do neoliberalismo. A falência dos grandes bancos e a retomada do protagonismo estatal na esfera econômica conduziram certos setores intelectuais e autoridades políticas a compactuarem com esta hipótese. Porém, as consequências da grande crise conduziram “a seu brutal fortalecimento, na forma de planos de austeridade adotados por Estados cada 
vez mais ativos na promoção da lógica da concorrência dos mercados financeiros" (2016, p. 13-14). Em outras palavras, parece que estávamos diante de um erro de diagnóstico.

De acordo com Dardot e Laval, outro erro de diagnóstico poderia ser localizado no final da década de 1970, quando se interpretava o neoliberalismo como uma ideologia ou como uma política econômica. Sem dúvida que os governos de Reagan e Thatcher davam mostras de sua nova forma econômica; porém, não seria possível compreender o neoliberalismo como uma simples retomada dos princípios liberais, do laissez-faire. Mais que agir no plano institucional, os autores sinalizam que o neoliberalismo também opera no plano subjetivo. “Em outras palavras, com o neoliberalismo, o que está em jogo é nada mais nada menos que a forma de nossa existência, isto é, a forma como somos levados a nos comportar, a nos relacionar com os outros e com nós mesmos" (Dardot e Laval, 2016, p. 16).

Inspirados na abordagem desenvolvida por Foucault, os pensadores derivam a tese estruturadora deste livro, qual seja: que o neoliberalismo configura-se como a nova "razão do mundo".

Devemos entender, por isso, que essa razão é global, nos dois sentidos que pode ter o termo: é "mundial", no sentido de que vale de imediato para o mundo todo, e, ademais, longo de limitar-se à esfera econômica, tende à totalização, isto é, a "fazer o mundo" por seu poder de integração de todas as dimensões da existência humana. Razão do mundo, mas ao mesmo tempo uma "razão-mundo" (Dardot e Laval, 2016, p. 16 - grifos no original).

Nesta direção, os autores reconhecem o neoliberalismo como uma racionalidade, para além de compreendê-lo apenas como um sistema econômico ou como uma ideologia. Em sua acepção, “a racionalidade neoliberal tem como característica principal a generalização da concorrência como norma de conduta e da empresa como modelo de subjetivação" (Dardot e Laval, 2016, p. 17). Nesta interlocução com o pensamento foucaultiano ${ }^{4}$ é que conseguem apontar alguns limites do marxismo para examinar o neoliberalismo, principalmente a questão de que não é possível explicá-lo desde uma lógica monocausal. O quadro normativo do neoliberalismo toma os indivíduos como alvos privilegiados e, “em nome da liberdade e apoiando-se nas margens de manobra concedidas aos indivíduos, orienta de maneira nova as condutas, as escolhas e as práticas desses indivíduos" (Dardot e Laval, 2016, p. 21).

A principal contribuição desta obra, em nossa leitura, está em mapear as variadas tecnologias de poder mobilizadas sobre as subjetividades no contexto do neoliberalismo. Diferentemente do sujeito da eficácia (do liberalismo) ou do sujeito produtivo (da sociedade industrial), o neoliberalismo fabrica um 
'neossujeito', que toma a empresa como modelo e a realização pessoal como projeto. Uma nova ética do trabalho parece delinear-se, não mais centrada na acumulação, mas em um 'dispositivo desempenho/gozo' combinando poder e liberdade. Importa explicar que a busca por desempenho e satisfação permanentes, ao articularem os discursos psicológico e econômico, tendem a desencadear um conjunto de efeitos patológicos.

Distanciando-se do diagnóstico de que a nova razão do mundo seja totalizadora, ainda que possa ter uma "fisionomia pessimista" (Dardot e Laval, 2015, p. 295), os autores vão em busca de possibilidades de resistência. Em interlocução com variados movimentos políticos (ecológicos, altermundialistas etc.), passam a investir no conceito de "comum". Na entrevista anteriormente citada, argumentam que "a emergência do 'comum' nas lutas abre para nós uma verdadeira saída e permite superar o dilema entre o retorno impossível à doutrina totalizante e o fatalismo impotente diante da dispersão das lutas" (2015, p. 312-313). Assim sendo, Dardot e Laval publicaram a obra Comum: ensaio sobre a revolução no século XXI, no ano de 2014, na França.

Como estratégia de contestação, em relação às variadas consequências derivadas da racionalidade neoliberal, o conceito de comum adquiriu uma formulação inicial por meio das lutas contra o capitalismo e o Estado. Este conceito - o comum - "tornou-se princípio efetivo dos combates e movimentos que há duas décadas resistem à dinâmica do capital e conduzem a formas originais de ação e discurso" (Dardot e Laval, 2017, p. 16). Não se configurando como uma inovação, o comum emergiu como uma forma de luta política, na contestação ao capitalismo, mas também contra as formas dominadoras do Estado. Tornou-se bandeira dos movimentos dos ecologistas e altermundialistas.

Em um momento inicial, tomava-se como referência o termo commons, referindo-se aos processos de cercamento dos recursos ambientais (e intelectuais) em variadas regiões do mundo. As teorizações de Michael Hardt e Antonio Negri, valendo-se também dos diálogos com estas lutas, tiveram o mérito de produzir uma forma mais política para o conceito - o comum, no singular - e aproximá-lo mais efetivamente da tradição crítica. Em síntese, o comum "se tornou a designação de um regime de práticas, lutas, instituições e pesquisas que abrem as portas para um futuro não capitalista" (Dardot e Laval, 2017, p. 18).

Em sua obra, Dardot e Laval propõem-se, então, a descrever o comum como um princípio político.

Os combates pela "democracia real", o "movimento das praças", as novas "primaveras" dos povos, as lutas estudantis contra a universidade capitalista, as mobilizações a favor do controle popular da distribuição de água não são eventos caóticos e aleatórios, erupções acidentais e passageiras, insurreições dispersas e sem 
objetivos. Essas lutas políticas obedecem à racionalidade política do comum, são buscas coletivas de formas democráticas novas (2017, p. 19 - grifos no original).

Considerar o comum como um princípio estruturante das lutas contemporâneas, ainda conforme os autores, implica alguns exercícios de revisão conceitual. Dardot e Laval mapeiam três sentidos predominantes. O primeiro refere-se a uma perspectiva teológica e posiciona o comum como "uma finalidade suprema das instituições políticas e religiosas" (2017, p. 27), isto é, como um fundamento da ação ética acerca do bem comum. O segundo sentido, por sua vez, tem uma natureza jurídica e preocupa-se em classificar os bens que poderiam ser designados como comuns. $\mathrm{O}$ ar, a água e os bens naturais, por exemplo, desde a Idade Média são considerados como bens impossíveis de serem apropriados individualmente. Por fim, o terceiro sentido diz respeito a uma perspectiva filosófica que, direta ou indiretamente, sugere uma vinculação entre o comum e o universal - isto é, supõe a possibilidade de pensar os elementos comuns à espécie humana. Importante salientar que Dardot e Laval argumentam que estas tendências aproximam-se do naturalismo e do essencialismo.

Ampliando esta compreensão, então, os pensadores franceses defendem que "somente a atividade prática dos homens pode tornar as coisas comuns, do mesmo modo que somente esta atividade prática pode produzir um novo sujeito de direitos" (Dardot e Laval, 2017, p. 53). O comum não seria um bem, uma virtude ou uma característica compartilhada, mas derivado de atividades práticas, de pessoas engajadas numa mesma tarefa.

O comum não é um bem, e o plural nada muda nesse aspecto, porque ele não é um objeto ao qual deva tender a vontade, seja para possuí-lo, seja para constituí-lo. O comum é o princípio político a partir do qual devemos construir comuns e ao qual devemos nos reportar para preservá-los, ampliá-los e lhes dar vida. É, por isso mesmo, o princípio político que define um novo regime de lutas em escala mundial (2017, p. 54).

O comum assim definido direciona-se para "uma questão de instituição" (Dardot e Laval, 2015, p. 313). Na entrevista anteriormente referida, Dardot e Laval argumentam que o importante "não é aquilo que é naturalmente bom, mas o que fazemos com que seja comum por um ato político, por um ato instituinte" (2015, p. 313). Seu horizonte político inscreve-se no âmbito da emancipação, ou seja, nas possibilidades de construir a si mesmo por meio da liberdade e da ação coletiva. Mais que isso, a instituição do comum pode conduzir à "emancipação como um projeto" (p. 309).

Ao procurar ultrapassar a racionalidade política neoliberal - descrita originalmente na obra $A$ nova razão do mundo - os pensadores franceses buscam em Comum - ensaio sobre a revolução no século XXI a possibilidade 
de teorizar sobre um conceito que possa servir como instrumento de luta na atualidade. Em um exercício de atualização do pensamento marxiano, Dardot e Laval estabelecem significativa interlocução com as teorizações sociais e com os movimentos sociais de nosso tempo. Suas reflexões sobre a atualidade de Marx remetem-se à potencialidade deste pensamento, na medida em que "ele é em si mesmo ativo ao produzir efeitos de inteligibilidade sobre o nosso mundo e, correlativamente, sobre a nossa situação no mundo" (Dardot e Laval, 2015, p. 301). Em outras palavras, um de seus principais méritos é a atualização "de um pensamento como pensamento" (p. 301). Na próxima seção, buscaremos delinear alguns traços conceituais do pensamento de Dardot e Laval para problematizar as relações entre trabalho, educação e juventude.

\section{Educação, juventude e trabalho: traços conceituais}

Após termos estabelecido um diagnóstico, de caráter pluralista, das condições sociais da contemporaneidade, bem como termos selecionado e apreciado analiticamente as obras de Dardot e Laval, neste momento buscaremos descrever alguns traços conceituais de suas obras que poderiam catalisar importantes reflexões para as relações entre educação, juventude e trabalho. A compreensão da crise como modo de vida permanente, a recente ênfase nos aspectos socioemocionais e as possibilidades de insurgências críticas e de construção do comum serão apresentados a seguir como estratégia para problematizar nosso objeto de interrogação e, na medida do possível, mapear alguns insights para a mobilização de futuras investigações.

\section{A compreensão da crise como modo de vida permanente}

A questão da universalização do acesso à escolarização para os jovens brasileiros ainda se configura como crucial. Apesar dos significativos investimentos políticos realizados nas últimas duas décadas, a quantidade de jovens afastados da escola e/ou com desempenho insuficiente merece atenção pública. O afastamento dos jovens das instituições escolares tem sido nomeado como 'crise de audiência' ou ainda como crise da legitimidade da própria escola (Krawczyk, 2011). Tais diagnósticos configuram-se como valiosos para examinar o acesso à formação escolar de nossos jovens; porém, com Laval e Dardot (2015), precisamos atentar para uma nuance específica do neoliberalismo, qual seja: a crise torna-se um modo de vida permanente e, mais que isso, uma estratégia de regulação subjetiva.

Desde a crise econômica de 2008, de acordo com os autores, podemos constatar uma "radicalização do neoliberalismo" (Laval e Dardot, 2017, p. 23), em que sua fórmula explicativa poderia ser simplificada em "quanto pior 
for mais deve continuar" (p. 23). O referido cenário conduziu a uma fragilização dos sistemas de proteção social, a uma intensificação da concorrência e à individualização das responsabilidades. Em tais condições, conforme apontamos acima, a crise torna-se a própria forma de governo, produzindo efeitos preocupantes.

Tudo isso tem como consequência a devastação social, ambiental e subjetiva que aumenta a raiva, o desespero e a resignação, as quais anunciam para amanhã formas políticas mais ou menos modernizadas do fascismo, de acordo com o sentido de abandono da população empobrecida (Laval e Dardot, 2017, p. 30).

No que tange às relações entre trabalho, educação e juventude - foco de nossa analítica - engendra-se uma generalização das formas de responsabilização dos atores, seja pelos seus percursos profissionais, seja por suas escolhas educacionais. De acordo com Silva (2018), no que se refere às políticas de juventude, "há um deslocamento das políticas de ajustamento da população juvenil aos sistemas de ensino, passando por políticas de contenção social, para a emergência de políticas com foco na customização dos percursos formativos" (p. 198). Em outras palavras, delineiam-se determinados dispositivos de articulação entre juventude e trabalho, ancorados na capacidade de escolha dos estudantes, dentre os quais a mais recente reforma do Ensino Médio no Brasil trata-se de um exemplar privilegiado.

\section{A ênfase nos aspectos emocionais e no dispositivo desempenho/gozo}

O reconhecimento da juventude como um conceito aberto e plural tratase de uma tendência importante nas atuais investigações desenvolvidas em nosso país (Carrano e Brenner, 2014). Distanciando-se da interpretação que a posiciona como uma mera etapa da vida, atualmente o jovem é reconhecido como um sujeito social, capaz de construir seus projetos de vida por meio da autonomia e do protagonismo. A esta compreensão, deveras importante, poderiam ser acrescentados os novos investimentos subjetivos realizados sobre as subjetividades contemporâneas, por meio da ênfase nos aspectos emocionais e da emergência do 'dispositivo desempenho/gozo' (Dardot e Laval, 2016). Isto é, as relações entre juventude e trabalho, produzidas no atual cenário capitalista, precisam ser explicadas de outros modos.

Em tais condições, Laval (2012) afirma que necessitamos de "novas armas teóricas para lutar contra a força das constatações e dos poderes que elas encarnam" (p. 13). Para o estudo crítico do neoliberalismo, sobretudo de suas dimensões subjetivas, torna-se necessário o desenvolvimento de uma "nova antropologia global do sujeito econômico" (p. 17). Mais que isso, trata-se de redescrever a construção das subjetividades. 
A tensão antes existente entre o competidor e o cidadão, entre o interesse econômico e o impulso benfeitor para os demais, tende a borrar-se. A figura humana se reunifica na construção do sujeito econômico, que desde este momento alcança a condição de empresa para o acesso de qualquer oportunidade de negócio em um contexto de absoluta e constante competitividade. Os âmbitos da política e da moral, os vínculos educativos, as relações cotidianas e a própria concepção que o indivíduo tem de si mesmo se veem profundamente afetados por esta generalização das formas empresariais (Laval, 2012, p. 19).

Os critérios de rentabilidade e de eficácia, coadunados aos sistemas avaliativos que deles se derivam, permitem-nos estender nossas reflexões entre juventude e trabalho para um novo conjunto valorativo emergente que, com maior ou menor intensidade, chega até nossas emoções. Resiliência, resignação, extroversão, comunicabilidade, empatia, adaptabilidade, dentre outros, tornam-se fatores indispensáveis para a formação educacional dos jovens. Não é à toa, em termos curriculares, que podemos constatar a centralidade da noção de competências socioemocionais no âmbito do capitalismo atual.

\section{As possibilidades de insurgências críticas e a reinscrição da formação juvenil no território do comum}

Em termos políticos, o conceito clássico para pensar a emancipação dos jovens é o protagonismo. Falou-se dos jovens construtores de sua própria história e, mais recentemente, das ações individualizadas destes sujeitos na política e na sociedade. Com Dardot e Laval (2017) podemos complexificar esta questão, acrescentando as possibilidades de insurgências críticas e a reinscrição da formação juvenil no território do comum. Outras estratégias de ação política parecem emergir da mobilização dos jovens na atualidade.

Entretanto, as formas emergentes de protagonismo juvenil são levadas adiante no contexto de intensificação do neoliberalismo, com sua ênfase na competitividade e na consequente "descoletivização da ação" (Dardot e Laval, 2017, p. 16). Uma das derivações deste cenário é a generalização da precariedade, nos variados âmbitos da vida social e subjetiva. Em termos educacionais, Barbosa (2018) auxilia-nos a melhor interrogar: "como se posicionar diante da precariedade manufaturada, socialmente induzida, quando a vida da maioria corre o risco de se tornar insuportavelmente precária, incerta ou insegura?" (p. 586). Ainda que revestidas deste protagonismo, as subjetividades juvenis, em nossa percepção, revestem-se de um generalizado sentimento de precariedade.

Em termos de luta política, tal como expomos na seção anterior, Dardot e Laval (2017) oferecem-nos um princípio político alternativo capaz de ultrapassar a gramática neoliberal, qual seja: o comum. 
Termo central da alternativa ao neoliberalismo, o "comum" tornou-se princípio efetivo dos combates e movimentos que há duas décadas resistem à dinâmica do capital e conduzem a formas originais de ação e discurso. Longe de ser pura invenção conceitual, é a fórmula de movimentos e correntes de pensamento que pretendem opor-se à tendência dominante de nossa época: a da ampliação da apropriação a todas as esferas da sociedade, da cultura e da vida. Nesse sentido, o termo "comum" designa não o ressurgimento de uma ideia comunista eterna, mas o surgimento de uma forma nova de contestar o capitalismo, ou mesmo de considerar sua superação (Dardot e Laval, 2017, p. 16-17 - grifos no original).

Baseado nos instrumentos conceituais derivados dos estudos políticos de Dardot e Laval, precisamos ponderar a necessidade de estudar as possibilidades de insurgências críticas que se derivam do protagonismo juvenil e a reinscrever a própria formação juvenil no território do comum. Isto implica, desde nosso entendimento, não reduzir as formas contemporâneas de protagonismo dos estudantes à mera capacidade de escolha. Antes disso, sugerese uma recomposição (e atualização) das práticas políticas e dos movimentos juvenis e dos estudos desenvolvidos em seu entorno.

\section{Considerações finais}

Ao longo do presente estudo, procuramos construir um diagnóstico crítico das relações entre trabalho, educação e juventudes contemporâneas, por meio de um breve diálogo com o pensamento social de Christian Laval e Pierre Dardot. Tal diagnóstico, em nossa perspectiva, adquire significativa potencialidade heurística para pensar o contexto brasileiro, na medida em que assistimos à constituição de uma 'nova morfologia do trabalho'(Antunes, 2014a), derivada do próprio processo de financeirização da economia que se estende para as variadas esferas da vida humana.

Nossa preocupação central, delineada por meio de um diagnóstico crítico - de caráter heterodoxo -, encontra-se na emergência de novos arranjos subjetivos no contexto do neoliberalismo. Ainda que esta preocupação se materialize em variadas tradições de pensamento, escolhemos construir este diagnóstico valendo-nos dos escritos recentes de Dardot e Laval. As obras destes estudiosos franceses adquiriram significativa relevância e ampla circulação acadêmica no Brasil.

Por fim, para pensar as relações entre trabalho, educação e juventudes contemporâneas, buscamos três traços conceituais nas obras recentes de Dardot e Laval. A compreensão da crise como modo de vida permanente, a ênfase nos aspectos emocionais e no dispositivo desempenho/gozo e a reinscrição da formação juvenil no território do comum serviram de ferramentas conceituais para problematizarmos nosso objeto de reflexão. Não restam dúvidas de que, 
por meio deste diagnóstico, é aberto um conjunto de inquietações a serem consideradas atentamente em estudos futuros. Como sinalizamos desde a epígrafe deste texto, nossos desafios imediatos continuam sendo o exame crítico e a proposição de alternativas para as mutações subjetivas provocadas pelo neoliberalismo (e suas derivações já sentidas em nosso país!).

\section{Financiamento}

Pesquisa financiada pelo Conselho Nacional de Desenvolvimento Científico e Tecnológico, Edital Universal 2018, processo n.: 420179/2018-6.

\section{TRABAJO, EDUCACIÓN Y JUVENTUDES: DIÁLOGO CON EL PENSAMIENTO SOCIAL DE CHRISTIAN LAVAL Y PIERRE DARDO}

Resumen El presente estudio teórico propone un diagnóstico crítico de las relaciones entre trabajo, educación y juventud contemporánea, por medio de un breve diálogo con el pensamiento social de Christian Laval y Pierre Dardot. Su preocupación central se encuentra en la emergencia de nuevos arreglos subjetivos en el contexto del neoliberalismo. Para pensar tales relaciones fueron considerados tres trazos conceptuales derivados de las obras de los autores seleccionados: la comprensión de la crisis como modo de vida permanente, el énfasis en los aspectos emocionales y en el dispositivo desempeño/gozo y la reinscripción de la formación juvenil en el territorio del común. A lo largo del estudio, se muestra que un referencial analítico crítico y heterodoxo, sustentado en una relectura específica del pensamiento de Marx articulada a otras contribuciones, de la forma como tratado por Dardot y Laval, presenta potencialidad heurística significativa para pensar los conceptos de trabajo, educación y juventud en el contexto brasileño actual.

Palabras clave educación; trabajo; juventud; sociología de la educación.

\section{Notas}

${ }^{1}$ Mesmo que efetivamente não sejam reconhecidos como pensadores educacionais, inúmeros estudos fazem uso das perspectivas teóricas de Dardot e Laval (Barbosa, 2018; Silva, 2018).

${ }^{2}$ No âmbito das políticas educacionais, esta hipótese é ampliada por Silva, Silva e Vasques (2018).

${ }^{3}$ Han (2014), em outra obra, expõe que "o regime neoliberal transforma a exploração alheia em autoexploração que afeta todas as classes" (p. 10).

${ }^{4}$ Em seu curso Nascimento da Biopolítica, ministrado no Collège de France no ano de 1980, o filósofo francês coloca sob análise a história do neoliberalismo como uma racionalidade orientadora da vida no Ocidente (Foucault, 2008). 


\section{Referências}

ANDRADE, Daniel; OTA, Nilton. Uma alternativa ao neoliberalismo: entrevista com Pierre Dardot e Christian Laval. Tempo Social, São Paulo, v. 27, n. 1, p. 275-315, 2015.

ANTUNES, Ricardo. Desenhando a nova morfologia do trabalho no Brasil. Estudos Avançados, São Paulo, v. 28, n. 81, p. 39-53, 2014a.

ANTUNES, Ricardo. A nova morfologia do trabalho e as formas diferenciadas da reestruturação produtiva no Brasil dos anos de 1990. Sociologia, Porto, v. 27, p. 11-25, 2014 b.

BARBOSA, Manuel Gonçalves. Educação, vida precária e capacitação. Educação e Sociedade, Campinas, v. 39, n. 144, p. 584-599, set. 2018.

BOLTANSKI, Luc; CHIAPELLO, Ève. O novo espírito do capitalismo. São Paulo: Editora WMF Martins Fontes, 2009.

CARRANO, Paulo C. R.; BRENNER, Ana K. Os sentidos da presença dos jovens no Ensino Médio: representações da escola em três filmes de estudantes. Educação e Sociedade, Campinas, v. 35, n. 129, p. 1.223-1.240, 2014.

DARDOT, Pierre; LAVAL, Christian. A nova razão do mundo: ensaio sobre a sociedade neoliberal. São Paulo: Boitempo, 2016.

DARDOT, Pierre; LAVAL, Christian. Comum: ensaio sobre a revolução no século XXI. São Paulo: Boitempo, 2017.

FOUCAULT, Michel. O Nascimento da Biopolítica. São Paulo: Martins Fontes, 2008.

FRIGOTTO, Gaudêncio. Os circuitos da história e o balanço da educação no Brasil na primeira década do século XXI. Revista Brasileira de Educação, Rio de Janeiro, v. 16, n. 46, p. 235254, jan.- abr. 2011.

GORZ, André. O imaterial: conhecimento, valor e capital. São Paulo: Annablume, 2005.
HAN, Byung-Chul. La sociedad del cansancio. Buenos Aires: Herder Editorial, 2012.

HAN, Byung-Chul. Psicopolitica: neoliberalismo e novas técnicas de poder. Buenos Aires: Herder Editorial, 2014.

HENNINGTON, Élida A.; CUNHA, Daisy M.; FISCHER, Maria C. B.. Trabalho, educação, saúde e outros possíveis: diálogos na perspectiva ergológica. Trabalho Educação e Saúde, Rio de Janeiro, v. 9, n. supl. 1, p. 5-18, 2011.

KRAWCZYK, Nora. Reflexão sobre alguns desafios do Ensino Médio no Brasil hoje. Cadernos de Pesquisa, São Paulo, v. 41, n. 144, p. 752-769, 2011.

KUENZER, Acácia. Da dualidade assumida à dualidade negada; o discurso da flexibilização justifica a inclusão excludente. Educação e Sociedade, Campinas, v. 28, n. 100, p. 1.153-1.178, 2007.

LAVAL, Christian. Pensar el neoliberalismo. In: AGAMBEN, Giorgio et al. (Eds.). Pensar desde la izquierda. Mapa del pensamiento critico para un tiempo en crisis. Madri: Errata Naturae, 2012. p. 11-24.

LIMA, Licínio. Aprender para ganhar, conhecer para competir: sobre a subordinação da educação na "sociedade da aprendizagem". São Paulo, Cortez: 2012.

LIMA, Licínio. A educação faz tudo? Crítica ao pedagogismo na sociedade de aprendizagem. Revista Lusófona de Educação, Lisboa, n. 15, p. 41-54, 2010.

LIPOVETSKY, Gilles. Metamorfoses da cultura liberal: ética, mídia e empresa. Porto Alegre: Sulina, 2004.

POCHMANN, Márcio. Desafios do desenvolvimento brasileiro. Educação e Sociedade, Rio de Janeiro, v. 24, n 124, p. 705-722, 2013. 
POCHMANN, Márcio. Brasil: segunda grande transformação no trabalho? Estudos Avançados, São Paulo, v. 28, n. 81, p. 23-38, 2014.

SAFATLE, Vladimir. Cinismo e falência da crítica. São Paulo: Boitempo, 2008.

SASSEN, Saskia. Expulsões: brutalidade e complexidade na economia global. São Paulo: Paz e Terra, 2016.

SAVIANI, Demerval. Trabalho e educação: fundamentos ontológicos e históricos. Revista Brasileira de Educação, Rio de Janeiro, v. 12, n. 34, p. 152-165, 2007.
SENNETT, Richard. A cultura do novo capitalismo. Rio de Janeiro: Record, 2006.

SILVA, Roberto D.; SILVA, Denílson; VASQUES, Rosane. Políticas curriculares e financeirização da vida: elementos para uma agenda investigativa. Revista de Estudos Curriculares, Minho, v. 9, n. 1, p. 5-23, 2018.

SILVA, Roberto D. A crise como operador estratégico e a emergência de novas figuras subjetivas: escolarização juvenil e a arte de governar neoliberal. In: RESENDE, Haroldo de (org.). Michel Foucault: a arte de governar neoliberal e a educação. São Paulo: Intermeios, 2018, p. 195-210. 